\title{
Research
}

\section{Enhancing collaboration in the UK animal welfare research community}

\author{
Michael Mendl, Richard Bennett, Lisa Collins, Anna Davies, \\ Paul Flecknell, Laura Green, Jane Hurst, Alistair Lawrence, \\ Poppy Statham, James Turnbull
}

THE UK Biotechnology and Biological Sciences Research Council (BBSRC) has funded a new Animal Welfare Research Network (AWRN) to bring together animal welfare researchers, those working in related fields and other professionals with an interest in animal welfare, including representatives from industry, charities and government. The core aims of the AWRN are to foster enhanced collaboration within the UK animal welfare research community and other relevant disciplines to: facilitate mentoring and training for

Michael Mendl, MA, PhD, FRSB,

e-mail: mike.mendl@bris.ac.uk

Anna Davies, BSc, PhD,

Poppy Statham, BSc, MSc, PhD,

University of Bristol, Langford, Bristol BS40 5DU, UK

Richard Bennett, BSc, MSc, PhD,

University of Reading, Reading RG6 6AR, UK

Lisa Collins, MA, DPhil, FRSB,

University of Lincoln, Lincoln LN6 7TS, UK

Paul Flecknell, MA, VETMB, PhD, DLAS, DipECVAA,

DipECLAM, FRSB(Hon), FRCVS,

Newcastle University, Newcastle Upon Tyne NE2 $4 \mathrm{HH}, \mathrm{UK}$

Laura Green, BVSc, MSc (Epid), PhD, MECVPH, FRSB, MRCVS,

University of Warwick, Warwick CV4 7AL, UK

Jane Hurst, BSc, PhD,

University of Liverpool, Liverpool CH64 7TE UK

Alistair Lawrence, BSc, DipRurSci, PhD,

SRUC, Easter Bush, Edinburgh EH25 9RG, UK

James Turnbull, BVMGS, MSc, PhD, FHEA, MRCVS,

University of Stirling, Stirling FK9 4LA, UK early career researchers; seek new ways of supporting welfare researchers at all career stages; encourage interaction between researchers and stakeholders to identify gaps and opportunities for joint-working; and promote the impact of research outcomes. Over $£ 100,000$ has been provided by BBSRC to fund the AWRN for three years in the first instance, and it will be managed by a coordinating group of animal welfare researchers led by Professor Michael Mendl from Bristol university.

Animal welfare is of high societal importance. In an EU survey, 34 per cent of approximately 29,000 citizens rated the protection of welfare in farmed animals as being of the highest importance. Within the UK this proportion was 38 per cent (EU 2007). Britain has a strong tradition of animal welfare research that dates back to the Brambell Committee's (1965) parliamentary report on the welfare of livestock kept under intensive conditions. This, in turn, was prompted by Ruth Harrison's (1964) book Animal Machines, an investigation into the rise of modern intensive farming methods.

Animal welfare research is, therefore, a relatively new discipline. It uses fundamental underpinning science in studies that aim, for example, to create new and more accurate ways to scientifically assess welfare or to increase our understanding of the biological responses of animals to challenges. At the same time, strategic science studies that focus 

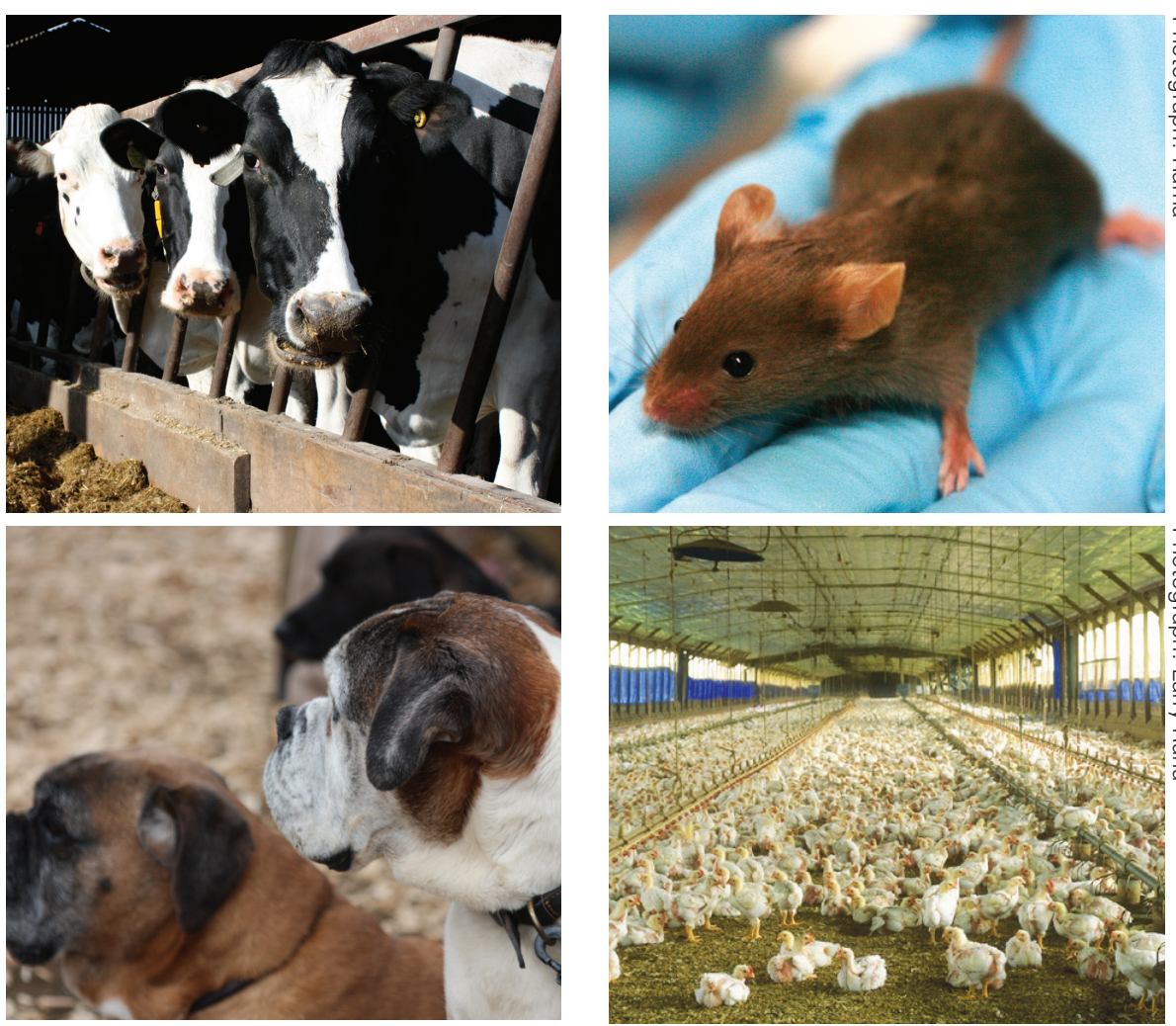

The Animal Welfare Research Network will be focused on research contributing to the welfare of managed animals, including farmed, laboratory and companion animals, and both vertebrates and relevant invertebrates. It will also encourage links to researchers working on non-managed species

on applying findings and developing ways of implementing change and improving welfare in the real world (eg, on farm) are also an important part of the discipline. Animal welfare researchers work with a range of species including farm, laboratory, companion, zoo and even wild animals.

An important objective of the AWRN is to promote greater interaction within the animal welfare research community via meetings, workshops and exchange of researchers. This will increase cohesion, awareness of the broad scope of work that is being carried out, and amalgamation of complementary skills in basic and applied research. A related objective is to create opportunities for research students and early career researchers to meet peers and colleagues, establish their own cross-institute activities and receive training from research groups with different expertise, including research areas currently outside the welfare envelope

Animal welfare researchers traditionally come from a range of backgrounds including biology, veterinary science, agricultural science, psychology, ethics, economics and philosophy. However, advances in fields such as genomics, neuroscience, computer science, epidemiology and social science can be highly relevant to animal welfare research too. For example, computervision methods are starting to be used to automatically monitor animal behaviour and detect welfare problems (Dawkins and others 2012). Considering this, another objective of the AWRN is to use symposia and workshop events to increase interaction and collaboration with researchers in other disciplines in order to develop new ways of assessing and improving welfare.

It is hoped that these activities will enhance cross-institutional partnerships, generate teams that can compete more effectively for national and international research funding, and develop new collaborative research programmes that will contribute both high-quality basic science and real-world impact.

Welfare considerations often dovetail with those of the communities that manage and use animals. For example, improvements in welfare will generally be accompanied by better growth and reproduction, and animals with poor welfare are unlikely to be the best subjects to use in scientific research. However, there can be conflicts of interest, particularly when welfare improvements come with additional costs to the user. Moreover, there may also be external pressure for changes that could actually threaten animal welfare. A current example of this is the potential for concerns about global food security to drive renewed intensification of livestock production (Garnett and others 2013). Animal welfare research can help to tackle some of these issues, especially if it is informed by constructive engagement with stakeholders, such as animal users and producers, animal charities and government and policymakers. Another important objective of the AWRN is, therefore, to bring together stakeholders and researchers to pinpoint timely research topics and gaps in existing knowledge, and identify how research findings can be implemented effectively alongside the economic, political and societal considerations that surround our use of animals.

As well as having clear practical implications, animal welfare research tackles some of the most intriguing and challenging questions in modern biology. How can we measure the emotional states of other animals given that a key determinant of welfare is the experience of states such as pleasure, pain, fear and anxiety? Which species are likely to have the capacity for conscious feelings? And are animals able to empathise with the experiences of others?

A final major objective of the AWRN is to develop a public-facing website to explain how these and other questions can be addressed scientifically, and to provide examples of the most exciting ongoing animal welfare research. The AWRN hopes to promote the strength and successes of UK animal welfare research as a discipline that genuinely, and unusually, spans from basic science to real-world application.

An AWRN website will be built in 2016. Readers who are interested in finding out more about the AWRN or in becoming a member can email: awrn-manager@bristol. ac.uk

\section{References}

BRAMBELL, F. W. R. (1965) Report of the Technical Committee to enquire into the Welfare of Animals kept under Intensive Livestock Husbandry Systems. HMSO DAWKINS, M. S., CAIN, R. \& ROBERTS, S. J. (2012) Optical flow, flock behaviour and chicken welfare. Animal Behaviour 84, 219-223

EU. (2007) Special Eurobarometer 270. Attitudes of EU Citizens Towards Animal Welfare.

GARNETT, T., APPLEBY, M. C., BALMFORD, A., BATEMAN, I. J., BENTON, T. G., BLOOMER, P. \& OTHERS. (2013) Sustainable intensification in agriculture: premises and policies. Science 341, 33-34.

HARRISON, R. (1964). Animal Machines. The New Factory Farming Industry. Vincent Stuart

doi: 10.1136/vr.i682

\section{Adoption of ARRIVE guidelines}

Veterinary Record has adopted the ARRIVE (Animal Research: Reporting In Vivo Experiments) guidelines, where appropriate, for research published in the journal.

The guidelines are intended to improve the reporting of animal experiments and are a 20-point checklist of the essential information that should be included in reporting animal research.

Further information can be found at www.nc3rs.org.uk/page. asp?id=1357 


\title{
Veterinary Enhancing collaboration in the UK animal welfare research community
}

Michael Mendl, Richard Bennett, Lisa Collins, Anna Davies, Paul Flecknell, Laura Green, Jane Hurst, Alistair Lawrence, Poppy Statham and James Turnbull

Veterinary Record 2016 178: 138-139

doi: $10.1136 / v r . i 682$

Updated information and services can be found at:

http://veterinaryrecord.bmj.com/content/178/6/138

\begin{abstract}
These include:
References This article cites 2 articles, 1 of which you can access for free at: http://veterinaryrecord.bmj.com/content/178/6/138\#BIBL

Email alerting Receive free email alerts when new articles cite this article. Sign up in the service box at the top right corner of the online article.
\end{abstract}

\section{Notes}

To request permissions go to:

http://group.bmj.com/group/rights-licensing/permissions

To order reprints go to:

http://journals.bmj.com/cgi/reprintform

To subscribe to BMJ go to:

http://group.bmj.com/subscribe/ 